\title{
Characterization of Thyroid Abnormalities in a Large Cohort of Children with Down Syndrome
}

\author{
Melinda J. Pierce ${ }^{\mathrm{a}}$ Stephen H. LaFranchi ${ }^{\mathrm{a}}$ Joseph D. Pinter ${ }^{\mathrm{b}}$ \\ a Department of Pediatrics, Division of Endocrinology, Oregon Health and Science University, Portland, OR, USA; \\ ${ }^{\mathrm{b}}$ Institute on Development and Disability, Oregon Health and Science University, Portland, OR, USA
}

\section{Keywords}

Down syndrome $\cdot$ Thyroid diseases $\cdot$ Congenital heart malformation · Congenital hypothyroidism · Screening

\begin{abstract}
Background/Aims: Thyroid disease is a common comorbidity in individuals with Down syndrome (DS), but historical studies have multiple limitations. We assessed thyroid abnormalities in a large cohort of children with DS. Methods: Retrospective records review from a single institution. Calculated prevalence of common thyroid abnormalities and associations with common comorbidities. Results: Among 508 patients, 120 (24\%) had a thyroid-related diagnosis, the majority having elevated thyrotropin treated with levothyroxine. A Kaplan-Meier estimate projects that 50\% have thyroid disorder by adulthood, with $20 \%$ of hypothyroidism diagnosed before the age of 6 months. When tested, approximately $50 \%$ had positive antithyroid antibodies, though this rate was $100 \%$ in overt hypothyroidism. There was no association between congenital or acquired hypothyroidism and common comorbidities. Conclusion: Thyroid disease in DS is more common and occurs earlier than in the general population, and is often transient. Thyroid disease is unrelated to gender, obesity, or other comorbidities. Apart from overt hypothyroidism, much of hypothyroidism in DS appears unre-
\end{abstract}

lated to autoimmunity; we recommend checking of antithyroid antibodies only in select cases. An additional screen for thyroid disease between the newborn screen and the 6-month well-child visit will detect early cases of hypothyroidism who passed their newborn screen.

(c) 2017 S. Karger AG, Basel

\section{Introduction}

Down syndrome (DS) is the most common autosomal aneuploidy with a national birth prevalence of 14.57 per 10,000 , or 1 in 691 , live births [1]. It is well established that patients with DS are at increased risk for the development of thyroid hormone abnormalities, with a reported prevalence between 8 and 49\%, depending on the definition of abnormality [2-18]. This includes all forms of thyroid disease: congenital hypothyroidism; acquired subclinical hypothyroidism; acquired overt hypothyroidism; and hyperthyroidism. The wide range is due to small patient numbers in historical studies, and though some recent studies have greater numbers, they lack diagnostic detail. Many studies also lack information related to possible associations of thyroid disease with other comorbidities, or were too small to reach statistical significance. The current American Academy of Pediatrics (AAP) guidelines

\section{KARGER}

(c) 2017 S. Karger AG, Basel

E-Mail karger@karger.com

www.karger.com/hrp
Melinda J. Pierce, MD

Oregon Health and Science University

Mail Code CDRC-P, 707 SW Gaines St.

Portland, OR 97239 (USA)

E-Mail piercme@ohsu.edu 
Table 1. Diagnostic criteria for types of thyroid disease

\begin{tabular}{ll}
\hline Thyroid disease & Diagnostic criteria" \\
\hline $\begin{array}{l}\text { Congenital hypothyroidism } \\
\text { Subclinical hypothyroidism } \\
\begin{array}{l}\text { Overt hypothyroidism } \\
\text { Isolated hyperthyrotropinemia }\end{array}\end{array}$ & $\begin{array}{l}\text { Diagnosed by newborn screen, or as stated in the electronic medical record } \\
\text { "High" TSH with normal FT4 at diagnosis } \\
\text { "High" TSH with low FT4 at any time } \\
\text { "High" diagnostic TSH without diagnostic FT4 or while off medication, or } \\
\text { as stated in the medical record } \\
\text { Diagnosis in electronic medical record of nonspecific hypothyroidism and/ } \\
\text { or prescribed levothyroxine; no diagnostic thyroid function tests available } \\
\text { Diagnosis in electronic medical record of Graves disease, hyperthyroidism, } \\
\text { or prescribed methimazole }\end{array}$ \\
\hline
\end{tabular}

${ }^{a}$ Representative reference ranges after 1 month of age are TSH $0.5-5.0 \mu \mathrm{IU} / \mathrm{mL}$ and FT4 $0.8-1.8 \mathrm{ng} / \mathrm{dL}$; however, classification of "high" and "low" was assessed for individual laboratory normal ranges.

on the care of patients with DS, based mainly on expert opinion, recommend screening for thyroid dysfunction at birth, 6 months, 12 months, and annually thereafter [19]. The absence of a solid evidence base has made criteria for diagnosis and treatment decisions, in cases of subclinical hypothyroidism in particular, a hotly debated topic in the pediatric endocrinology literature.

The goals of this study are to better characterize the timing and prevalence of thyroid abnormalities in children with DS, to compare age at diagnosis between different types of thyroid disease, and to reexamine the screening recommendations. This study also investigates biochemical thyroid status, autoimmunity, treatment decisions, and possible related comorbidities. Of particular interest was the evaluation of the prevailing wisdom that most thyroid diseases in DS are both permanent and related to autoimmunity [20].

\section{Methods}

The Child Development and Rehabilitation Center at Oregon Health and Science University (OHSU) sees pediatric patients with DS primarily from Oregon and Washington in a multidisciplinary team setting. A retrospective review of the electronic medical record (EMR) revealed 508 eligible patients seen in the DS clinic between the clinic opening in November 2007 through January 2015. Fifty-seven additional patients with DS and a thyroid-related ICD-9 visit code were identified in the OHSU Pediatric Endocrine Clinic (PEC), though 2 were ultimately not diagnosed with thyroid disease. Data from PEC patients were added to DS clinic data to increase power in association analyses but were not used in prevalence calculations. Study data were collected and managed using
REDCap (Research Electronic Data Capture) electronic tools hosted at the OHSU. REDCap is a secure, web-based application that supports data capture for research studies, providing (1) interfaces for validated data entry; (2) audit trails for tracking data manipulation and export procedures; and (3) automated export for data downloads. Approval for this study was obtained from the OHSU Institutional Review Board.

Demographic data included gender, ethnicity, and primary language at home. Ethnicity was determined by patient report, was retrieved from the EMR, and was assessed in the study because of possible differences in rates of autoimmunity or other comorbidities. Historic health information included karyotype, history and type of thyroid disease, age and thyroid function tests (TFTs) at the time of diagnosis, presence and type of antithyroid antibodies, treatment, history and type of cardiac disease and surgical interventions, and other notable comorbidities. Anthropometric data at visits included height, weight, and body mass index (BMI) as well as height, weight, and BMI percentiles for age. Height and weight percentiles were based on the DS growth charts from Cronk et al. [21]. BMI percentiles were based on Center for Disease Control growth charts for patients older than 2 years [22].

Thyroid disease was characterized as congenital hypothyroidism, subclinical hypothyroidism, overt hypothyroidism, isolated hyperthyrotropinemia, unknown hypothyroidism, and hyperthyroidism according to the criteria in Table 1 as defined by the American Thyroid Association [23]. Although there potentially are differences in treatment practices with mildly elevated thyrotropin (TSH) levels, biochemical evidence of subclinical hypothyroidism was used to define cases where available when treatment was initiated by outside providers prior to evaluation in our clinics. To account for variability in treatment practices, we have further separated cases of presumed subclinical hypothyroidism into those with TSH above the normal cutoff but below the commonly accepted treatment threshold of $10 \mu \mathrm{IU} / \mathrm{mL}$ and those with TSH greater than $10 \mu \mathrm{IU} / \mathrm{mL}$. In cases where diagnostic data were unavailable, classification was made based on abnormal TFTs, if available, within 6 months before starting treatment. All "un- 
Table 2. Demographics and comorbid diagnoses for children seen in the DS clinic $(n=508)$ and PEC $(n=57)$

\begin{tabular}{|c|c|c|c|c|}
\hline & \multicolumn{2}{|l|}{ DS clinic } & \multicolumn{2}{|l|}{ PEC } \\
\hline & $n$ & $\%$ & $n$ & $\%$ \\
\hline Mean age, years (range) & \multicolumn{2}{|l|}{$6.5(0.05-26)$} & \multicolumn{2}{|l|}{$11.4^{\mathrm{a}}(0.2-28)$} \\
\hline \multicolumn{5}{|l|}{ Gender } \\
\hline Male & 282 & 55.5 & 25 & 44 \\
\hline Female & 226 & 44.5 & 32 & 56 \\
\hline \multicolumn{5}{|l|}{ Ethnicity $(n=494)$} \\
\hline Non-Hispanic/Latino & 336 & 68.0 & 43 & 80 \\
\hline Hispanic/Latino & 158 & 32.0 & 11 & 20 \\
\hline \multicolumn{5}{|l|}{ Karyotype $(n=448)$} \\
\hline $47, \mathrm{XX} / 47, \mathrm{XY}$ & 420 & 93.8 & 14 & \\
\hline $46 X X, t(14 ; 21) / 46 X Y, t(14 ; 21)$ & 6 & 1.3 & & \\
\hline Other (mosaic, other translocations) & 22 & 4.9 & & \\
\hline Unknown & 60 & & 43 & \\
\hline \multicolumn{5}{|l|}{ Primary language at home $(n=506)$} \\
\hline English & 372 & 73.5 & 44 & 79 \\
\hline Spanish & 109 & 21.5 & 10 & 18 \\
\hline Other & 25 & 4.9 & 2 & 4 \\
\hline \multicolumn{5}{|l|}{ Congenital cardiac disease } \\
\hline No & 160 & 31.5 & 27 & $47^{\mathrm{b}}$ \\
\hline Yes & 348 & 68.5 & 30 & 52 \\
\hline Required surgery & 145 & $41.6^{\mathrm{c}}$ & 13 & $43^{c}$ \\
\hline Visual impairment (including astigmatism, strabismus) & 312 & 61.4 & 24 & $42^{\mathrm{b}}$ \\
\hline Hearing impairment (including pressure equalization tubes) & 270 & 53.2 & 24 & 42 \\
\hline Sleep apnea & 154 & 30.3 & 14 & 25 \\
\hline Gastrointestinal atresia (duodenal, anal, other) & 27 & 5.3 & 5 & 9 \\
\hline Seizure disorder & 26 & 5.1 & 3 & 5 \\
\hline Autism spectrum disorder & 25 & 4.9 & 3 & 5 \\
\hline Undescended testicles (one or both; males only) & 21 & 7.5 & & \\
\hline Celiac disease & 19 & 3.7 & 4 & 7 \\
\hline Hirschsprung disease & 14 & 2.8 & 2 & 4 \\
\hline Leukemia/myeloproliferative disorder & 15 & 3.0 & 5 & $9^{b}$ \\
\hline Type I diabetes & 4 & 0.8 & 4 & $7^{\mathrm{b}}$ \\
\hline
\end{tabular}

a Two-sided $t$ test, $p<0.05$. ${ }^{\mathrm{b}} \chi^{2}$ test, $p<0.05$ comparing the DS clinic and PEC, cardiac disease and visual impairment are more common in the DS clinic, leukemia and type I diabetes are more common in the PEC. ${ }^{c}$ Percent of patients requiring cardiac surgery is taken only from patients with cardiac disease.

known" patients on levothyroxine were counted among those with "acquired hypothyroidism" when applicable.

For comparisons between 2 groups, including percentage of patients tested for autoimmunity, percentage of those testing positive, and differences in levothyroxine doses, a 2-sided $t$ test was used. Logistic regression was used to evaluate associations between thyroid disease and age, gender, ethnicity, presence of cardiac disease, BMI percentile, weight and weight percentile, and presence of gastrointestinal anomalies (Hirschsprung disease, duodenal atresia, and other gastrointestinal atresias). Because of collinearity, regression was repeated with cardiac surgery or cardiopulmonary bypass in place of cardiac disease. The Wald test was used to compare individual variables for significant associations. Linear regression was used to evaluate differences in weight-based levothyroxine dose between subclinical and overt hypothyroidism. Within each subgroup, analysis was done with $\chi^{2}$ comparison, except when groups were smaller than 5 , in which case the Fisher exact test was used. All statistical analyses were performed using STATA 14.1 software (StataCorp, College Station, TX, USA).

\section{Results}

\section{Prevalence and Summary Statistics}

Five hundred and sixty-five patients were included in the study: 508 patients in the DS clinic and 57 patients in the PEC (Table 2). There was a slight male predominance (54\%) and a high number of patients identified as Hispanic/Latino(a) (31\%). The cohort is similar to published cohorts of patients with DS with regard to karyotype and 
Table 3. Prevalence of different types of thyroid disease ${ }^{a}$

\begin{tabular}{|c|c|c|c|c|c|}
\hline Thyroid disease & $\begin{array}{l}\text { DS } \\
\text { clinic, } n\end{array}$ & PEC, $n$ & Age at diagnosis & $\begin{array}{l}\text { Mean TSH at diagnosis, } \mu \mathrm{IU} \\
\mathrm{mL} \text { (range) }\end{array}$ & $\begin{array}{l}\text { / Mean FT4 at diagnosis, } \\
\text { ng/dl (range) }\end{array}$ \\
\hline Congenital hypothyroidism & $10(2 \%)$ & 4 & $1.5 \mathrm{~m}(n=13)$ & $52.7(15.66-109.5)(n=8)$ & Total T4:b $6.95(3.9-9.8)(n=8)$ \\
\hline TSH $5-10 \mu \mathrm{IU} / \mathrm{mL}$ & 30 & 12 & 5 yr $3 \mathrm{~m}$ & 7.9 & 1.05 \\
\hline $\mathrm{TSH}>10 \mu \mathrm{IU} / \mathrm{mL}$ & 22 & 12 & $5 \mathrm{yr} 7 \mathrm{~m}$ & 16.2 & 1.01 \\
\hline Overt hypothyroidism & $5(1 \%)$ & 4 & 7 yr $11 \mathrm{~m}(n=9)$ & $52.1(21.6-150)(n=9)$ & $0.43(0.1-0.75)(n=9)$ \\
\hline $\mathrm{TSH}>10 \mu \mathrm{IU} / \mathrm{mL}$ & 5 & 1 & $2 \mathrm{yr} 4 \mathrm{~m}$ & 22.5 & \\
\hline Unknown hypothyroidism & $22(4.3 \%)$ & 10 & $4 \mathrm{yr} 4 \mathrm{~m}(n=23)$ & & \\
\hline Hyperthyroidism & $8(1.6 \%)$ & 8 & 8 yr $11 \mathrm{~m}(n=16)$ & $0.02(0.008-0.1)(n=15)$ & $3.64(1.0-6.5)(n=15)$ \\
\hline Total & $120(24 \%)$ & 55 & & & \\
\hline
\end{tabular}

\footnotetext{
yr, years; m, months.
}

${ }^{a}$ Diagnostic data for age, mean TSH, and mean free thyroxine (FT4) at diagnosis are taken from all patients for whom the data were available. ${ }^{\mathrm{b}}$ Total T4 values from newborn screen, instead of FT4, are reported for congenital hypothyroidism cases. ${ }^{c} 13 / 28$ patients with isolated hyperthyrotropinemia did not have diagnostic TSH available but did have an elevated TSH recorded within 6 months of treatment.

common comorbidities (Table 1). Patients in the PEC were older and less likely to have a reported history of cardiac disease, though rates of cardiac surgery were not different between the clinics. The PEC had a higher percentage of patients with leukemia/myeloproliferative disease and type I diabetes.

There were 422 patients without a thyroid-related diagnosis who had TSH and free thyroxine (FT4) recorded within 6 months of a visit, resulting in 648 TSH and FT4 measurements in total. This excludes any children diagnosed with thyroid disease based on TFTs at the visit in question. Mean TSH was $3.30 \mu \mathrm{IU} / \mathrm{mL}$ (range 0.04-9.66). Mean FT4 was 1.04 ng/dL (range 0.6-2.0).

As shown in Table 3, 120 (24\%) patients in the DS clinic had a documented history of thyroid-related diagnosis: $2 \%$ congenital hypothyroidism, $10 \%$ subclinical hypothyroidism, $1 \%$ overt hypothyroidism, $4.5 \%$ with isolated hyperthyrotropinemia, $4.3 \%$ unknown hypothyroidism, and $1.6 \%$ hyperthyroidism. There was no difference in rates of any type of thyroid disease between males and females; mean serum TSH and FT4 at diagnosis are shown in Table 3. There was a statistically significant difference in TSH and mean FT4 between those with overt and subclinical hypothyroidism $(p<0.005)$. All those with hyperthyroidism were diagnosed with Graves disease and treated with methimazole with good response to therapy.

For all patients, the median age at diagnosis with any thyroid disease was 4 years and 10 months. For any acquired hypothyroidism, there was no statistical difference in age at diagnosis between those with subclinical and those with overt hypothyroidism. Among those diagnosed with hypothyroidism outside of newborn screening, 11 patients (7.5\% of all acquired hypothyroidism) were diagnosed before the 6-month screening recommended by the AAP, although indications for testing earlier were not determined. For hyperthyroidism, median age at diagnosis was just under 9 years. The odds of developing thyroid disease increased by $10 \%$ per year with increasing age. Using a Kaplan-Meier estimate for the development of thyroid disease, it is estimated that $25 \%$ of patients with DS will carry a diagnosis of thyroid dysfunction by age 7.5 years and projected that up to $50 \%$ will by the time they reach adulthood (Fig. 1). This projection agrees with our clinical data, where at a mean age of 7 years at the time of the visit $24 \%$ of the patients had thyroid disease. When analysis is repeated and restricted only to patients with $\mathrm{TSH}>10 \mu \mathrm{IU} / \mathrm{mL}$ at diagnosis, $25 \%$ of patients will have thyroid dysfunction by 10 years of age, but $50 \%$ are still predicted to be affected by adulthood.

\section{Associations with Comorbidities}

Logistic regression for the odds of developing any thyroid disease and congenital hypothyroidism or acquired hypothyroidism separately showed no relationship to gender, history of cardiac disease or cardiac surgery, need for cardiopulmonary bypass, BMI weight or height percentile, or presence of gastrointestinal anomalies. The ab- 


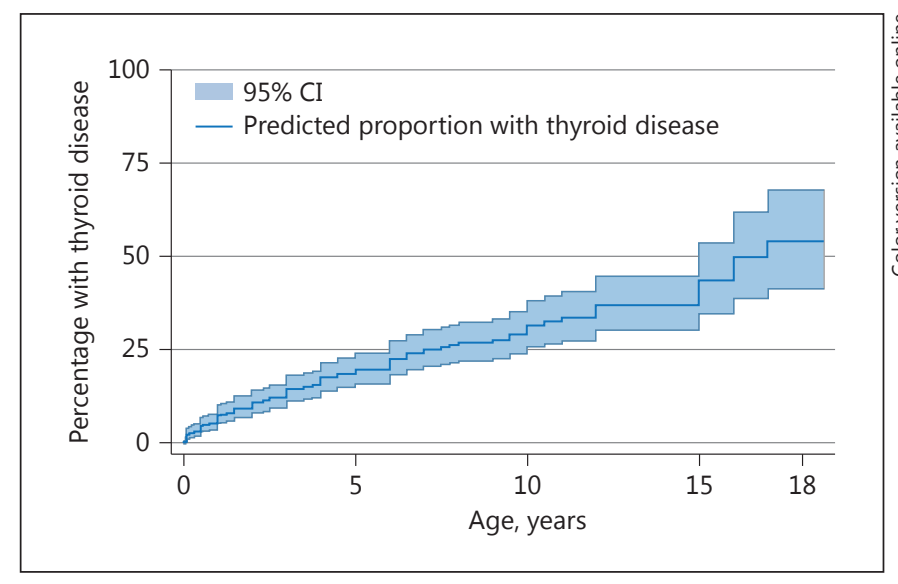

Fig. 1. Kaplan-Meier curve showing the prevalence of any type of thyroid disease in the pediatric Down syndrome population.

sence of association held when looking at only those with acquired hypothyroidism and TSH $>10 \mu \mathrm{IU} / \mathrm{mL}$. There was an increased risk for thyroid disease in those with type I diabetes, though this was weighted to patients seen in the PEC.

\section{Autoimmunity and Differences between Subclinical and Overt Hypothyroidism}

A total of 99 patients had antithyroid antibodies tested, with $46(46 \%)$ having any positive antibody (Table 4 ). Half of patients with positive antibodies had only 1 antibody present and 6 (13\%; all with hyperthyroidism) had more than 2. There were no differences in rates of antibody positivity between males and females ( $\chi^{2}$ test, $p=$ 0.2 ). Of those with diagnosis of acquired hypothyroidism, 62 had antibodies tested and 29 (47\%) were positive. It was unclear in EMR documentation whether antibody positivity impacted diagnostic decisions. Of those with positive antibodies, 15/29 with acquired hypothyroidism and $7 / 15$ with hyperthyroidism developed antibody positivity before the age of 8 years, including 2 patients with anti-thyroperoxidase (antiTPO) antibodies detected at 10 and 14 months, respectively.

Patients were equally likely to be tested for antibodies across all forms of acquired hypothyroidism. However, amongst those tested, patients with overt hypothyroidism and those with TSH $>10 \mu \mathrm{IU} / \mathrm{mL}$ were more likely to be antibody positive. For the population without thyroid dysfunction, 22 were tested for antithyroid antibodies with only $2 / 22$ having any positive test.
Table 4. Rates of antithyroid antibody testing and antibody positivity by diagnosis

\begin{tabular}{lcc}
\hline Diagnosis & $\begin{array}{l}\text { Antibodies } \\
\text { tested }\end{array}$ & $\begin{array}{l}\text { Antibodies } \\
\text { positive }\end{array}$ \\
\hline Subclinical hypothyroidism & $37 / 76(49 \%)$ & $17 / 37(46 \%)$ \\
TSH 5-10 $\mu \mathrm{IU} / \mathrm{mL}$ & $25 / 42(59 \%)^{\mathrm{b}}$ & $9 / 25(36 \%)$ \\
TSH > $10 \mu \mathrm{IU} / \mathrm{mL}$ & $12 / 34(35 \%)$ & $8 / 12(66 \%)$ \\
Overt hypothyroidism & $5 / 9(55 \%)$ & $5 / 5(100 \%)^{\mathrm{a}}$ \\
Isolated hyperthyrotropinemia & $12 / 28(43 \%)$ & $4 / 12(33 \%)^{\mathrm{a}}$ \\
TSH 5-10 $\mu \mathrm{IU} / \mathrm{mL}$ & $6 / 9(66 \%)$ & $1 / 6(17 \%)$ \\
TSH > 10 $\mu \mathrm{IU} / \mathrm{mL}$ & $6 / 19(32 \%)$ & $3 / 6(50 \%)$ \\
Unknown hypothyroidism & $8 / 32(25 \%)$ & $3 / 8(38 \%)$ \\
Hyperthyroidism & $15 / 16(94 \%)$ & $15 / 15(100 \%)$ \\
No thyroid dysfunction & $22 / 390(5.6 \%)$ & $2 / 22(10 \%)$ \\
\end{tabular}

a Statistically significant difference in proportions of positive antibodies between subclinical and overt hypothyroidism and isolated hyperthyrotropinemia and overt hypothyroidism. $p=0.02$ and 0.01 . No difference in antibody positivity between subclinical hypothyroidism and isolated hyperthyrotropinemia. ${ }^{b} \chi^{2}$ comparison shows those with TSH 5-10 $\mu \mathrm{IU} / \mathrm{mL}$ more likely to be tested, $p<0.05$, but no statistical difference in antibody positivity. When isolated hyperthyrotropinemia and subclinical hypothyroidism are analyzed together, there is no difference in antibody testing between TSH subgroups, but antibody positivity is more common in those with TSH $>10 \mu \mathrm{IU} / \mathrm{mL}\left(\chi^{2}\right.$ test, $p=0.049$ ).

\section{Thyroid Hormone Dosing}

Patients with TSH $>11 \mu \mathrm{IU} / \mathrm{mL}$ appeared to require a $0.5 \mathrm{mg} / \mathrm{kg} /$ day higher dose of levothyroxine when controlling for gender, age, and weight (95\% CI $0.2-0.8 \mathrm{mg} /$ $\mathrm{kg}, p=0.001)$.

\section{Transient Cases}

Of note, 18 patients with a diagnosis of hypothyroidism ( $1 / 14$ congenital, $10 / 76$ subclinical, $4 / 28$ isolated hyperthyrotropinemia, and 3/32 unknown) were not on therapy and had normal TSH and FT4 at their most recent screening. There was 1 case of remission in the patients diagnosed with Graves disease. There were no significant differences in rates of nontreatment between diagnoses. The highest recorded diagnostic TSH for all transient cases was $13.6 \mu \mathrm{IU} / \mathrm{mL}$. Almost half $(8 / 18)$ were diagnosed at or before the age of 3 years. Of these, 4 had measurements of antithyroid antibodies in the EMR, with 2 having positive antibodies. For those diagnosed after the age of 3 years, 5/6 tested had positive antibodies. As a sensitivity analysis, repeat analyses of differences in antibody testing and positivity between types of hypothyroidism, as discussed above, did not change conclusions when excluding those with transient hypothyroidism. 


\section{Discussion}

\section{Prevalence and Summary Statistics}

This study confirms the previously reported high prevalence of thyroid disease in patients with DS. The majority of our patients have mild, subclinical hypothyroidism or hyperthyrotropinemia without measurement of FT4. Unlike the general population, there is no female predominance for any type of thyroid disorder, including hyperthyroidism. When looking at all types of thyroid disease, both treated and untreated, up to $50 \%$ of patients with DS are expected to have a diagnosis of thyroid disease by adulthood.

Our study appears to confirm a relatively high prevalence of congenital hypothyroidism in children with DS. All patients were diagnosed by newborn screen, most often with a primary total T4 of less than the 10th percentile and elevated TSH [24]. The majority of these cases are presumed to be permanent. The prevalence in the DS clinic population of 1:50 (2\%), as shown in Table 3, is similar to rates seen in other studies $[3,6,25]$. TSH by newborn screen blood spot was available for $8 / 14$ and suggested milder disease with only moderately elevated $\mathrm{TSH}$, though all but 1 were still on levothyroxine replacement at a mean age of 6 years at follow-up. Although an association between congenital hypothyroidism and gastrointestinal anomalies has been suggested previously, in this larger study, no patients with congenital hypothyroidism had duodenalatresia, anal atresia, orHirschsprung disease $[3,26]$.

The high rate of diagnosis after newborn screen but before the age of 6 months suggests a nonimmune thyroid dysfunction in infancy. This early dysfunction is also supported by the finding that more than half of patients diagnosed with hypothyroidism are diagnosed before the age of 5 years. This early dysfunction could be a mild form of congenital hypothyroidism that escapes detection by newborn screen, as suggested in earlier, smaller studies, though more conclusive studies would be needed to confirm this hypothesis $[25,27]$. In congenital hypothyroidism, it is well established that every month without thyroid hormone supplementation worsens developmental outcomes at school age $[28,29]$. If an additional screening for hypothyroidism were added at the routine well-child visits at 6-8 weeks and at 4 months for children with DS, this could improve the developmental trajectory of some patients without adding additional physician visits for the family.
Autoimmunity and Differences between Subclinical and Overt Hypothyroidism

Rates of autoimmunity in those without thyroid disease, as indicated by antithyroid antibody positivity, were lower than previously reported. This may be sampling bias as those with minor abnormalities in TFTs may have been more likely to be labeled as hypothyroid if they had positive antibodies. Rates of positivity in our study population for antiTPO were much higher than for antithyroglobulin. In the general population, antibody positivity for either is approximately $10 \%$, though antiTPO is more likely to be associated with biochemical thyroid disease [30]. Although a previous study showed no cases of antibody positivity in early childhood in DS, we found that almost half of patients with positive antibodies developed them before the age of 8 years [8]. There was also no difference in antibody positivity between males and females. When sorted by degree of TSH elevation or FT4 depression, antibody positivity did not impact levothyroxine requirements, though higher diagnostic TSH seemed to be associated with antibody positivity and all patients with low FT4 had evidence of autoimmunity when measured.

Some authors have argued that patients with DS have a nonpathological shift in the normal range of TSH and that perhaps this leads to overdiagnosis of subclinical hypothyroidism [31, 32]. Indeed, Meyerovich et al. [32] reported a normal TSH reference range for healthy patients with DS to be $1.5-8.9 \mu \mathrm{IU} / \mathrm{mL}$. Our data showed a lower upper limit of normal with 2.5 standard deviations above the mean for TSH of $7.1 \mu \mathrm{IU} / \mathrm{mL}$. Diagnostic TSH in subclinical hypothyroidism overlapped with this range but mean TSH was higher in those labeled as having hypothyroidism. However, even in cases where TSH was clearly elevated, FT4 was maintained in the normal range in all but 9 of 83 patients in whom it was measured. TSH also did not appear to be greatly affected by obesity as seen in the general population [33]. When tested, much of subclinical hypothyroidism does not appear to be autoimmune mediated, though the rates of antibody positivity are higher in all groups than reported for the US healthy adult population [30].

\section{Transient Cases}

Thirteen percent of patients with a history of hypothyroidism were not receiving treatment and had normal TFTs, despite high rates of antibody positivity when tested. Similar high rates of normalization of TSH elevation are also found in the general population and have been reported in those with DS, though typically associated with absence of autoimmune disease [34, 35]. In congenital hypothyroidism, the disease is also more likely to be 
transient in patients with DS [36]. Combined, these factors suggest that TSH elevation may be transient in a significant portion of patients including those diagnosed in the first year of life. Patients may be mislabeled as having permanent hypothyroidism and will be subject to more frequent laboratory testing and physician follow-up.

It has been suggested in 1 randomized controlled trial of patients with DS that treatment in the first 2 years of life results in small benefits in growth and gross motor development at 24 months, but there was no difference at follow-up at the age of 10 years $[37,38]$. The idea that there could be benefit and little harm may result in physicians being more likely in this vulnerable population to treat transient TSH elevations without waiting for a confirmatory second test. This bias towards treatment increases the rate of recorded diagnoses of thyroid disease in the DS population. The interpretation becomes selfperpetuating and is flawed, as the increased rate of diagnosis is likely due to the application of a different diagnostic treatment threshold compared to the general population rather than a true difference in disease rates. We posit that this greater likelihood of diagnosing a normal patient with thyroid disease may be mitigated by delaying diagnosis of subclinical hypothyroidism until more than 1 sample over 2-3 months suggests sustained TSH elevation, though greater caution and clinical judgement may be required in children under the age of 3 years.

There are multiple limitations to the current study. All patients were seen in specialty clinics that potentially draw more complex patients, although rates of common comorbidities were similar to other published cohorts $[11,12]$. Diagnosis of thyroid disease was made by outside providers in most cases, including decisions regarding interpretation of TFTs. Results for TSH and FT4 came from multiple institutions. Although there was a broad overlap between the normal ranges from different laboratories, the reported means should be interpreted with caution as laboratories do not share the same reference standards. There was a moderate amount of missing diagnostic data including TFTs for the 32 patients classified as "unknown hypothyroidism." Finally, a relatively small number of patients were screened for antithyroid antibodies, particularly among those labeled as not having thyroid disease.

\section{Conclusion}

We believe our data support the conclusion that high rates of hypothyroidism are evidence of inherent dysfunction of the thyroid axis in patients with DS. Given the significant number of patients diagnosed before the age of 6 months, we recommend additional screening of TSH and FT4 between newborn screening and the currently recommended 6-month screen (e.g., around 2-3 months of age), though a further study is warranted to determine the optimal timing for this test. While patients would otherwise be detected at the currently recommended 6-month screen, with these additional tests most, if not all, patients, with early hypothyroidism not detected on newborn screen would be started on critical therapy earlier. Approximately 100 patients would need to be screened to detect 1 case of infantile hypothyroidism. Although compliance with routine screening is low, the additional points of testing could theoretically improve rates of any testing being done in the first year [10].

We also encourage recognition that all hypothyroidism is potentially transient. Particularly in patients diagnosed before the age of 3 years, we recommend management similar to that for congenital hypothyroidism: consideration of a structured trial off therapy with recheck of TSH and FT4 in 4 weeks in patients who have not had a rise in TSH $>10 \mu \mathrm{IU} / \mathrm{mL}$ on treatment nor required increases in levothyroxine dose after initiation of therapy $[24,39]$.

It would appear that most, if not all, cases of severe hypothyroidism with low FT4 and cases of hyperthyroidism are secondary to autoimmune thyroid disease. However, evidence of autoimmunity was not predictive of thyroid disease severity in the absence of significant elevations in TSH and may not be useful in the diagnosis of acquired hypothyroidism in DS in cases with a single test showing mild TSH elevation. We recommend testing only in cases where this would assist in decisions regarding treatment, with the caveat that even cases with positive antithyroid antibodies may have transient disease. Repeat testing of TSH and FT4 in 2-3 months should be considered before a decision is made to treat what could be a transient biochemical finding.

\section{Acknowledgements}

Salary support was given for M. Pierce provided in part by the National Institutes of Health Training Grant T32HD007497. REDCap Database was managed by the Oregon Clinical and Translational Research Institute and supported by the National Center for Advancing Translational Science of National Institutes of Health under grant 1 UL1 RR024140 01. 
The authors have no financial relationships relevant to this article to disclose. The authors have no conflicts of interest to this article to disclose.

The authors would like to acknowledge Daniel Pinter for assistance with data collection and Katrina Ramsey, MPH for advice on statistical analysis. Ms. Ramsey is supported by the Oregon Clinical and Translational Research Institute, with funding by the National Center for Advancing Translational Science of National Institutes of Health under grant 1 UL1 RR024140 01.

\section{Author Contributions}

Dr. Pierce conceptualized and designed the study and data collection instruments, performed data collection, drafted the initial manuscript, and approved the final manuscript as submitted. Dr. Pierce had full access to all the data in the study and takes responsibility for the integrity of the data and the accuracy of the data analysis. Dr. LaFranchi provided critical feedback in the development of the study, reviewed and revised the manuscript, and approved the final manuscript as submitted. Dr. Pinter assisted with the conceptualization and design of the study, reviewed and revised the manuscript, and approved the final manuscript as submitted.

\section{References}

1 Parker SE, Mai CT, Canfield MA, Rickard R, Wang Y, Meyer RE, Anderson P, Mason CA, Collins JS, Kirby RS, Correa A; National Birth Defects Prevention Network: Updated National Birth Prevalence estimates for selected birth defects in the United States, 2004-2006. Birth Defects Res A Clin Mol Teratol 2010;88: 1008-1016.

2 Claret C, Goday A, Benaiges D, Chillaron JJ, Flores JA, Hernandez E, Corretger JM, Cano JF: Subclinical hypothyroidism in the first years of life in patients with Down syndrome. Pediatr Res 2013;73:674-678.

3 Cutler AT, Benezra-Obeiter R, Brink SJ: Thyroid function in young children with Down syndrome. Am J Dis Child 1986;140:479-483.

4 Dinani S, Carpenter S: Down's syndrome and thyroid disorder. J Ment Defic Res 1990;34(Pt 2):187-193.

5 Gibson PA, Newton RW, Selby K, Price DA, Leyland K, Addison GM: Longitudinal study of thyroid function in Down's syndrome in the first two decades. Arch Dis Child 2005;90: 574-578.

6 Gruneiro de Papendieck L, Chiesa A, Bastida MG, Alonso G, Finkielstain G, Heinrich JJ: Thyroid dysfunction and high thyroid stimulating hormone levels in children with Down's syndrome. J Pediatr Endocrinol Metab 2002;15:1543-1548.

-7 Iughetti L, Predieri B, Bruzzi P, Predieri F, Vellani G, Madeo SF, Garavelli L, Biagioni O, Bedogni G, Bozzola M: Ten-year longitudinal study of thyroid function in children with Down's syndrome. Horm Res Paediatr 2014;82:113-121.

-8 Karlsson B, Gustafsson J, Hedov G, Ivarsson SA, Anneren G: Thyroid dysfunction in Down's syndrome: relation to age and thyroid autoimmunity. Arch Dis Child 1998;79:242245.

9 Loudon MM, Day RE, Duke EM: Thyroid dysfunction in Down's syndrome. Arch Dis Child 1985;60:1149-1151.

10 McGowan S, Jones J, Brown A, Reynolds L, Leyland K, Charleton P, Rahim M, Mansor M, Ritha S, Donaldson M; Scottish Down Syn- drome Thyroid Screening Group: Capillary TSH screening programme for Down's syndrome in Scotland, 1997-2009. Arch Dis Child 2011;96:1113-1117.

-11 Roizen NJ, Magyar CI, Kuschner ES, Sulkes SB, Druschel C, van Wijngaarden E, Rodgers L, Diehl A, Lowry R, Hyman SL: A community cross-sectional survey of medical problems in 440 children with Down syndrome in New York State. J Pediatr 2014;164:871-875.

-12 Schieve LA, Boulet SL, Boyle C, Rasmussen SA, Schendel D: Health of children 3 to 17 years of age with Down syndrome in the 1997-2005 national health interview survey. Pediatrics 2009;123:e253-e260.

-13 Mihci E, Akcurin G, Eren E, Kardelen F, Akcurin S, Keser I, Ertug H: Evaluation of congenital heart diseases and thyroid abnormalities in children with Down syndrome. Anadolu Kardiyol Derg 2010;10:440-445.

-14 Moosa S, Segal DG, Christianson AL, Gregersen NE: Thyroid dysfunction in a cohort of South African children with Down syndrome. S Afr Med J 2013;103:966-970.

15 Pueschel SM, Pezzullo JC: Thyroid dysfunction in Down syndrome. Am J Dis Child 1985; 139:636-639.

16 Tuysuz B, Beker DB: Thyroid dysfunction in children with Down's syndrome. Acta Paediatr 2001;90:1389-1393.

17 Rubello D, Pozzan GB, Casara D, Girelli ME, Boccato S, Rigon F, Baccichetti C, Piccolo M, Betterle C, Busnardo B: Natural course of subclinical hypothyroidism in Down's syndrome: prospective study results and therapeutic considerations. J Endocrinol Invest 1995;18: $35-40$.

18 Murphy J, Philip M, Macken S, Meehan J, Roche E, Mayne PD, O’Regan M, Hoey HM: Thyroid dysfunction in Down's syndrome and screening for hypothyroidism in children and adolescents using capillary TSH measurement. J Pediatr Endocrinol Metab 2008;21:155-163.

19 Bull MJ; Committee on Genetics: Health supervision for children with Down syndrome. Pediatrics 2011;128:393-406.
20 Dallas JS: Hypothyroidism; in Lipfshitz F (ed): Pediatric Endocrinology. New York, Marcel Dekker, 2003, pp 359-406.

-21 Cronk C, Crocker AC, Pueschel SM, Shea AM, Zackai E, Pickens G, Reed RB: Growth charts for children with Down syndrome: 1 month to 18 years of age. Pediatrics $1988 ; 81$ : 102-110.

22 Centers for Disease Control and Prevention, National Center for Health Statistics: CDC Growth Charts: United States. 2000. https:// www.cdc.gov (accessed February 27, 2017).

23 Jonklaas J, Bianco AC, Bauer AJ, Burman KD, Cappola AR, Celi FS, Cooper DS, Kim BW, Peeters RP, Rosenthal MS, Sawka AM; American Thyroid Association Task Force on Thyroid Hormone Replacement: Guidelines for the treatment of hypothyroidism: prepared by the American Thyroid Association Task Force on thyroid hormone replacement. Thyroid 2014;24:1670-1751.

24 Leger J, Olivieri A, Donaldson M, Torresani T, Krude H, van Vliet G, Polak M, Butler G; Espe Pes Slep Jspe Apeg Appes I; Congenital Hypothyroidism Consensus Conference Group: European Society for Paediatric Endocrinology consensus guidelines on screening, diagnosis, and management of congenital hypothyroidism. Horm Res Paediatr 2014;81:80-103.

25 Purdy IB, Singh N, Brown WL, Vangala S, Devaskar UP: Revisiting early hypothyroidism screening in infants with Down syndrome. J Perinatol 2014;34:936-940.

26 Jaruratanasirikul S, Patarakijvanich N, Patanapisarnsak C: The association of congenital hypothyroidism and congenital gastrointestinal anomalies in Down's syndrome infants. J Pediatr Endocrinol Metab 1998;11: 241-246.

27 van Trotsenburg AS, Vulsma T, van Santen HM, Cheung W, de Vijlder JJ: Lower neonatal screening thyroxine concentrations in down syndrome newborns. J Clin Endocrinol Metab 2003;88:1512-1515.

28 Fisher DA, Foley BL: Early treatment of congenital hypothyroidism. Pediatrics 1989;83: 785-789.
Thyroid Abnormalities in Down Syndrome
Horm Res Paediatr 2017;87:170-178 
29 Klein AH, Meltzer S, Kenny FM: Improved prognosis in congenital hypothyroidism treated before age three months. J Pediatr 1972;81:912-915.

- 30 Hollowell JG, Staehling NW, Flanders WD, Hannon WH, Gunter EW, Spencer CA, Braverman LE: Serum TSH, T(4), and thyroid antibodies in the United States population (1988 to 1994): National Health and Nutrition Examination Survey (NHANES III). J Clin Endocrinol Metab 2002;87:489-499.

31 Prasher V, Haque MS: Misdiagnosis of thyroid disorders in down syndrome: time to reexamine the myth? Am J Ment Retard 2005;110:23-27.

-32 Meyerovitch J, Antebi F, Greenberg-Dotan S, Bar-Tal O, Hochberg Z: Hyperthyrotropinaemia in untreated subjects with Down's syndrome aged 6 months to 64 years: a comparative analysis. Arch Dis Child 2012;97:595598.

33 Reinehr T: Obesity and thyroid function. Mol Cell Endocrinol 2010;316:165-171.
- 34 Wasniewska M, Salerno M, Cassio A, Corrias A, Aversa T, Zirilli G, Capalbo D, Bal M, Mussa A, De Luca F: Prospective evaluation of the natural course of idiopathic subclinical hypothyroidism in childhood and adolescence. Eur J Endocrinol 2009;160:417-421.

35 Selikowitz M: A five-year longitudinal study of thyroid function in children with Down syndrome. Dev Med Child Neurol 1993;35: 396-401.

36 Oakley GA, Muir T, Ray M, Girdwood RW, Kennedy R, Donaldson MD: Increased incidence of congenital malformations in children with transient thyroid-stimulating hormone elevation on neonatal screening. J Pediatr 1998;132:726-730.

37 van Trotsenburg AS, Vulsma T, van Rozenburg-Marres SL, van Baar AL, Ridder JC, Heymans HS, Tijssen JG, de Vijlder JJ: The effect of thyroxine treatment started in the neonatal period on development and growth of two-year-old Down syndrome children: a randomized clinical trial. J Clin Endocrinol Metab 2005;90:3304-3311.
38 Marchal JP, Maurice-Stam H, Ikelaar NA, Klouwer FC, Verhorstert KW, Witteveen ME, Houtzager BA, Grootenhuis MA, van Trotsenburg AS: Effects of early thyroxine treatment on development and growth at age 10.7 years: follow-up of a randomized placebocontrolled trial in children with Down's syndrome. J Clin Endocrinol Metab 2014;99:E2722-E2729.

39 American Academy of Pediatrics, Rose SR; Section on Endocrinology and Committee on Genetics, American Thyroid Association, Brown RS; Public Health Committee Lawson Wilkins Pediatric Endocrine Society; Foley T, Kaplowitz PB, Kaye CI, Sundararajan S, Varma SK: Update of newborn screening and therapy for congenital hypothyroidism. Pediatrics 2006;117:2290-2303. 